\title{
Growth and Non-Specific Immune Responses of Asian Seabass (Lates calcarifer) Fed on Commercial and Mixed Pure Nucelotides Diet
}

\author{
Sri Dwi Hastuti ${ }^{1,2}$, James Munro ${ }^{1}$, and Stephen Pyecroft ${ }^{1}$ \\ ${ }^{1}$ School of Animal and Veterinary Sciences, University of Adelaide Australial \\ Email : sri.hastuti@adelaide.edu.au \\ ${ }^{2}$ Department of Aquaculture, Faculty of Agriculture and Animal Husbandry, University of \\ Muhammadiyah Malang Indonesia/ Email : hastuti@umm.ac.id
}

\begin{abstract}
Sri Dwi Hastuti, James Munro, and Stephen Pyecroft. 2016. Growth and Non-Specific Immune Responses of Asian Seabass (Lates calcarifer) Fed on Commercial and Mixed Pure Nucelotides Diet. Aquacultura Indonesiana, 17 (2): 69-74. Asian seabass (Lates calcarifer) aquaculture is a potential developing industry in Australia and Indonesia. As the aquaculture industry intensifies, the occurrence of significant diseases becomes more likely. Hence, it is important to find better methods for controlling diseases in this industry. Research on mammals and fish have previously demonstrated the potential benefits of dietary nucleotides to enhance immune function of the animal to combat diseases. However there is still very limited study of this subject in Asian seabass. This study aimed to investigate the role of dietary nucleotides on the growth and immune responses of Asian seabass. Juvenile Asian seabass with an average weight of $13.8 \pm 1.29$ (mean \pm SD) g were fed three different diets containing either Optimun ${ }^{\circledR}$ nucleotide or a mix of pure nucleotides at $2.5 \mathrm{~g} / \mathrm{kg}$ feed $(0.25 \%)$ and one basal diet (nucleotide free diet). Fish were fed at 3\% BW per day for 28 days. Results showed that dietary nucleotides did not significantly effect the growth, survival rate, and immune responses of the fish. However Optimun ${ }^{\circledR} \operatorname{diet}$ gave higher result in terms of growth, leucocrit level, lysozyme activity and respiratory burst activity of head kidney leucocyte compare to basal and the mix of pure nucleotide diets.
\end{abstract}

Keywords : Asian seabass; Growth; Immune responses; Nucleotide diet; Survival rate

\section{Introduction}

Disease in aquaculture can have significant impacts on production. Disease outbreaks usually occur when fish are stressed because of a variety of highly interconnected factors, including intensification strategies such as implementing high stocking density as well as the use of formulated feeds, trading of fish globally, and poor nutritional diets (BondadReantaso et al., 2005).

Current strategies for treatment of bacterial diseases in aquaculture commonly rely upon the use of antibiotics, however this can potentiate the development of antibiotic-resistant bacterial strains, potentially impact the nontarget bacterial communities and increase the risk of antibiotic residues in aquaculture products (Cabello, 2006). Therefore, alternative methods are needed to prevent these types of diseases. For example, optimal nutrition which can increase the effectiveness of the animals immune system to combat diseases. Low et al. (2003) stated that supplementation of exogenous nucleotides through the diet can help maintain the normal physiological status of the cultured animal and reduce negative impacts during stressful conditions. Nucleotides are low molecular weight biological compounds that play major roles in almost all biological processes (Barros et al., 2015). These substances are most important in the production of new cells since they can optimise the function of rapidly dividing tissues (Low et al., 2003). Other functions of nucleotide are to encode and decode genetic information, structure coenzymes components, as well as to form cellular agonists (Carver and Walker, 1995; Shiau et al., 2015).

Sakai (1999) reported that carp fed on a diet supplemented with nucleotides from yeast RNA experienced an increase of non-specific immune responses, such as phagocytosis of kidney leucocytes, production of superoxide, serum lysozyme activity and complement activity. Fish also increased their resistance to Aeromonas hydrophila. Tahmasebi-Kohyani et al. (2012) reported that feeding Rainbow trout (Oncorhynchus mykiss) with a supplemented nucleotide diet increased growth and resistance to disease from the stress caused by handling and crowding.

Dietary nucleotides supplementation in finfish have positive results in growth rates (Lin et al., 2009; Tahmasebi-Kohyani et al., 2011; Tahmasebi-Kohyani et al., 2012), survival rates against bacterial chalenged (Burrells et al., 2001 ${ }^{\mathrm{a}}$; 
Burrells et al., 2001 ; Cheng et al., 2011; Lin et al., 2009), immune responses (Burrells et al., 2001 ; Cheng et al., 2011; Lin et al., 2009; Sakai et al., 2001; Tahmasebi-Kohyani et al., 2011), stress tolerance (Burrells et al., 2001 ; Tahmasebi-Kohyani et al., 2011, 2012; Yousefi et al., 2012), and physiology or morphology of gastrointestinal (Burrells et al., 2001 ${ }^{\mathrm{b}}$; Cheng et al., 2011; Peng et al., 2013).

Asian seabass (Lates calcarifer) is an important economic commodity in the Asia Pacific region including Australia and Indonesia. Currently, there is little studied on the role of dietary nucleotides on Asian seabass. Therefore, the objectives of this study were to evaluate growth and immune responses of Asian seabass fed diet supplemented with either commercial and pure mixed nucleotides.

\section{Materials and Methods}

\section{Diet Preparation}

This study used two diets containing either Optimun ${ }^{\circledR}$ nucleotide or mix pure nucleotides at $2.5 \mathrm{~g} / \mathrm{kg}$ feed $(0.25 \%)$ and one basal diet (nucleotide free diet). Kenari et al. (2013) stated that the best dose of nucleotides in their research was $0.25 \%$. Optimun ${ }^{\circledR}$ nucleotide was supplied by Chemoforma, Switzerland. The mixture of five pure nucleotides which consist of adenosine monophosphate (AMP), uridine monophosphate (UMP), cytidine monophosphate (CMP), inosine monophosphate (IMP) and guanosine monophosphate (GMP) with the ratio (1:1:1:1:1) were purchased from Sigma Aldrich Germany. Basal diet in the form of feed mash was supplemented with the nucleotides at the specific doses. They were mixed together using a hand mixer and then by using a pelleting machine, formed into fish pellets. The pellet was oven dried and stored in the plastic bags at $4{ }^{\circ} \mathrm{C}$ until feeding. Table 1 shows the formulation and proximate composition of the diet.

\section{Feeding Trial and Blood sampling}

Asian seabass juveniles with an average weight of $13.8 \pm 1.29$ (mean \pm SD) $g$ from a local hatchery (South Australia) were used in this experiment. Upon arrival, fish were acclimated to laboratory condition for one week. Five fish were maintained in each $65 \mathrm{~L}$ tanks during 28 days of trial. Fish were fed at 3\% BW (body weight) per day. At the end of the feeding trial, fish weigh gained and survival rate were calculated. Blood was taken from the caudal vein by syringe from three fish and pooled for haematological and immunological assays. The blood sample was centrifuged at $3000 \mathrm{~g}$ for 15 minutes. Serum was collected and stored at $-80^{\circ} \mathrm{C}$ until analyzed.

Table 1. Formulation and proximate composition of the basal diet

\begin{tabular}{ll}
\hline Ingredient (percent in diet) & 70 \\
Fish meal & 15 \\
Fish oil & 14.15 \\
Wheat & 0.5 \\
Vitamin and mineral premix & 0.1 \\
Yttrium oxide & 0.25 \\
Nucleotide (Optimun/Mixed pure nucleotide) & \\
Proximate composition (percent in diet) & 94.7 \\
Dry matter content & 9.89 \\
Ash & 49.0 \\
Crude protein & 20 \\
Crude lipid & 1.85 \\
Fiber & \\
Vitamin and mineral premix includes (IU kg)1 or g kg)1 of premix): \\
vitamin A, 2.5MIU; vitamin D3, 0.25 MIU; vitamin E, $16.7 \mathrm{~g}$; \\
vitamin K3, 1.7 g; vitamin B1, 2.5 g; vitamin B2, 4.2 g; vitamin B3, \\
25 g; vitamin B5, 8.3; vitamin B6, 2.0 g; vitamin B9, 0.8; vitamin \\
B12, 0.005 g; biotin, 0.17 g; vitamin C, 75 g; choline, 166.7 g; \\
inositol, 58.3 g; ethoxyquin, 20.8 g; copper, 2.5 g; ferrous iron, 10.0 \\
g; magnesium, 16.6 g; manganese, 15.0 g; zinc, 25.0 g.
\end{tabular}

\section{Hematocrit and leucocrit assays}

Hematocrit and leucocrit assay were performed as method by Siwicki et al. (1994). Briefly a blood sample was placed in a micro hematocrit capillary tube to $2 / 3$ the volume of the tube. One end of the tube was closed with clay and then centrifuged for 5 minutes at 15,000 rpm. Erythrocyte and leucocyte column height were measured by a hematocrit reader and the values were expressed in \% of total sample.

\section{Lysozyme activity assay}

The lysozyme activity protocol was adapted from (Ellis, 1990) with slight modifications. In microplates 96 wells, the lysozyme activity assay was initiated by mixing $10 \mu \mathrm{L}$ serum and $10 \mu \mathrm{L}$ buffer $(0.05 \mathrm{M}$ sodium phosphate buffer, $\mathrm{pH}$ 6.2) with $130 \mu \mathrm{L}$ of lyophilized Micrococcus lysodeikticus (Sigma) suspension at a concentration of $0.6 \mathrm{mg} / \mathrm{mL}$ in sodium phosphate buffer, $\mathrm{pH}$ 6.2. The difference in absorbance at $450 \mathrm{~nm}$ was monitored between 0 minute and 10 minutes and used to calculate lysozyme activity.

\section{Respiratory burst activity assay}

The superoxide anion (respiratory burst activity) was evaluated by the procedure as 
described by (Secombes, 1990). Briefly, head kidney was removed from two fish, then leucocytes were isolated. Cell suspensions were prepared by pushing the tissue through nylon (mesh size $100 \mu \mathrm{m}$ ) with L-15 containing 100 $\mu \mathrm{L} / \mathrm{mL}$ penicillin/streptomycin, $10 \mu \mathrm{L} / \mathrm{mL}$ heparin and 2\% (v/v) FBS and then was layered onto $34 \%$ and $51 \%$ Percoll density gradient. The cells were centrifuged at $450 \mathrm{~g}$ for 30 minutes at $4^{\circ} \mathrm{C}$. After centrifugation, the bands of leucocytes above the $34-51 \%$ interfaces were collected and washed twice, counted and adjusted to the required cell number for the assay. One hundred $\mu \mathrm{L}$ of the cells suspension at concentration of $10^{6}$ cells $/ \mathrm{mL}$ were deposited in wells of 96-well plates and were incubated for two hours at $20^{\circ} \mathrm{C}$. Aliquots of $100 \mu \mathrm{L}$ of $0.2 \%$ nitroblue tetrazolium (NBT, Sigma) were dissolved in L-15 and $0.2 \mu \mathrm{L}$ phorbol 12 -myristate 13 -acetate $(1 \mathrm{mg} / \mathrm{mL})$ was added to each well, and then was incubated for a hour at room temperature. Medium was then carefully removed from the plate and then the cells was fixed by adding 100\% methanol and incubating for 10 minutes. Subsequently, the cells were washed twice with $70 \%$ methanol to remove unreduced NBT, and air-dried. Reduced NBT was dissolved by adding $120 \mu \mathrm{L}$ of $2 \mathrm{M}$ $\mathrm{KOH}$, followed by $140 \mu \mathrm{L}$ DMSO. The production of superoxide anion was expressed as the absorption value at $630 \mathrm{~nm}$ using $\mathrm{KOH}$ and DMSO as blanks.

\section{Data Analysis}

Each diet was fed to three groups of fish according to a completely randomized design. Results were analysed by one-way analysis of variance (ANOVA) using SPSS statistical software and significant was set at $P<0.05$.

\section{Results}

The effects of dietary nucleotide supplementation on growth, survival rate, and innate immune responses of Asian seabass serum are presented in Table 2 . There was no significant difference in growth, survival rate, and immune responses among treatments $(P>0.05)$. It is noted however that diet supplemented with Optimun ${ }^{\circledR}$ gave higher result comparing to basal and mixture pure nucleotide diet in terms of growth, leucocrit level, lysozyme and respiratory burst activity. The highest final weight was found on Optimun ${ }^{\circledR}$ diet with the average of final weight was $10.98 \pm 3.47 \mathrm{~g}$. The highest haematocrit level was $35.28 \pm 3.69 \%$ which was found in basal diet, while the highest level of leucocrit was $1.31 \pm 0.17 \%$ which was found in Optimun ${ }^{\circledR}$ diet. The highest lysozyme activity of serum and respiratory burst activity of head kidney macrophage were also found in diet supplemented with Optimun ${ }^{\circledR}$ with the value of $11.2 \pm 6.6 \mu \mathrm{g} / \mathrm{mL}$ and $0.146 \pm 0.027$, respectively.

Table 2. Performance of Asian seabass bass fed diets containing $0.25 \%$ nucleotides for 28 days

\begin{tabular}{|c|c|c|c|c|c|c|}
\hline Diets & $\begin{array}{l}\text { Weight } \\
\text { gain }(\mathrm{g})\end{array}$ & $\begin{array}{l}\text { Survival } \\
\text { Rate }(\%)\end{array}$ & $\begin{array}{c}\text { Hematocr } \\
(\%)\end{array}$ & $\begin{array}{l}\text { Leucocr } \\
(\%)\end{array}$ & $\begin{array}{c}\text { Lysozyme } \\
\text { activity } \\
(\mu \mathrm{g} / \mathrm{mL})\end{array}$ & $\begin{array}{l}\text { Respiratory } \\
\text { burst } \\
\text { activity } \\
\text { (OD 630) }\end{array}$ \\
\hline $\begin{array}{l}\text { Basal } \\
\text { (control) }\end{array}$ & $\begin{array}{l}9.44 \pm \\
2.45\end{array}$ & $\begin{array}{c}86.67 \pm \\
11.55\end{array}$ & $\begin{array}{c}35.28 \pm \\
3.69\end{array}$ & $\begin{array}{c}0.69 \pm \\
0.92\end{array}$ & $10.3 \pm 5.6$ & $\begin{array}{c}0.132 \pm \\
0.004\end{array}$ \\
\hline Optimun & $\begin{array}{c}10.98 \pm \\
3.47\end{array}$ & $\begin{array}{c}80.00 \pm \\
34.64\end{array}$ & $\begin{array}{c}32.03 \pm \\
3.44\end{array}$ & $\begin{array}{c}1.31 \pm \\
0.17\end{array}$ & $11.2 \pm 6.6$ & $\begin{array}{c}0.146 \pm \\
0.027\end{array}$ \\
\hline $\begin{array}{l}\text { Mix } \\
\text { nucleotides }\end{array}$ & $\begin{array}{c}9.89 \pm \\
2.32\end{array}$ & $\begin{array}{c}80.00 \pm \\
0.00\end{array}$ & $\begin{array}{c}28.50 \pm \\
13.28\end{array}$ & $\begin{array}{c}0.43 \pm \\
0.44\end{array}$ & $5.3 \pm 3.8$ & $\begin{array}{c}0.129 \pm \\
0.012\end{array}$ \\
\hline
\end{tabular}

None of the values (mean \pm SD of three replications) are significantly different $(P<0.05)$

\section{Discussion}

It has been reported that dietary nucleotides enhance humoral and cellular immunity. Dietary nucleotides improve the disease resistance, stress tolerance, growth rates and immune responses in teleost fish (Burrells et al., 2001 ${ }^{\mathrm{b}}$ ). Results from this current study showed no significant differences between growth of animals fed basal or nucleotide supplemented diets. This is similar to other studies where the inclusion of dietary oligonucleotides from yeast RNA for hybrid striped bass revealed no significant difference in growth performance compare to fish fed basal diet (Li and Gatlin, 2007), while Barros et al. (2015) reported that there were no significantly effect on Nile tilapia fed nucleotide diet compare with control diet.

Welker et al. (2011) found that nucleotides supplementation did not affect weight gain and survival rate of Channel catfish, while (Li et al., 2005) reported there was no significant differences in weight gain and survival among juvenile Red drum fed nucleotide diet at $0.25 \%$. Similar results have been found that feeding juvenile Red drum and Turbot with nucleotide diet did not affect growth rate of the fish (Fuchs et al., 2015; Li et al., 2005). In contrast, other experiment deal with dietary nucleotides in several species gave a positive result in growth rate of the animals such as reported on Atlantic salmon (Burrells et al., 2001 ${ }^{\mathrm{b}}$ ), juvenile Red drum (Cheng et al., 2011; Li and Gatlin, 2007), 
and juvenile Rainbow trout (Tahmasebi-Kohyani et al., 2011).

In this study, dietary nucleotides did not significantly influence haematological profile of Asian seabass. This finding is consistent with study conducted by Barros et al. (2015) which showed that haematological and immunological of Nile tilapia were not influenced by diet supplemented with nucleotides. On the other hand, Yousefi et al. (2012) demonstrated that Beluga sturgeon fed nucleotide diet at $0.35 \%$ gave the highest haematocrit level in their study.

Dietary nucleotides can have a positive influence on disease resistance, stress tolerance, and immune responses in teleost fish (Burrells et al., 2001 b). Peng et al. (2013) reported Turbot fed mixed pure nucleotide for 60 days increased significantly immune responses parameters in terms of respiratory burst, lysozyme and serum superoxide dismutase (SOD) activity. Similarly, Cheng et al. (2011) found there was significant increase in lysozyme and respiratory burst activity of Red drum fed diet which supplemented with commercial nucleotide. However, in this study no significant differences were found on serum lysozyme activity and respiratory burst activity of head kidney macrophage of Asian seabass fed dietary nucleotides. The same result was also found in Barros et al. (2015) who studied the effect of nucleotide diet on Nile tilapia. They stated that dietary nucleotides did not affect immune response parameters of Nile tilapia. However, they found that nucleotides could increase resistance of fish to Aromonas hydrophila. Similar result was found in catfish fed diet supplemented with pure nucleotide mixture at level $0.1-2.7 \%$ did not significantly reduced serum lysozyme activity compared with baseline levels (Welker et al., 2011). The facts that dietary nucleotides did not give significant effect on Asian seabass immunity maybe because the basal diet used has already contained levels of nucleotides derived from fish meal. It is reported that fish meal is rich of purines and pyrimidine bases (Gatlin and $\mathrm{Li}, 2007$ ). Interestingly, in this study Optimun ${ }^{\circledR}$ diet gave higher result on growth, leucocrite level, lysozyme activity and respiratory burst activity of head kidney leucocyte compare to other diets. It might be because commercial nucleotide such as Optimun ${ }^{\circledR}$ is derived from yeast which contain components such as trace elements and polysaccharides which can also influence growth and immune parameters of fish (Welker et al.,
2011). Siwicki et al. (1994) and Oliva-Teles and Goncalves (2001) mentioned yeast by products as natural diet additives could positively influence non-specific immune responses as well as growth.

It was found that administration of commercial nucleotides in diets at concentrations of $2 \mathrm{~g} / \mathrm{kg}$ of feed for 24 days, enhanced the resistance of Red-tail black shark against Streptococcus iniae (Russo and Yanong, 2006). Concentrations at $2 \mathrm{~g} / \mathrm{kg}$ feed was also found to be the optimum dose for juvenile Pacific white shrimp (Andrino et al., 2012). Lin et al. (2009) stated that $0.1-0.15 \%$ of mixtured pure nucleotides increased the superoxide anion $\left(\mathrm{O}_{2^{-}}\right)$ production, and it was found that the nucleotide AMP at $0.15 \%$ was more effective in enhancing immune response of Grouper. TahmasebiKohyani et al. (2011) suggested administration of Optimun ${ }^{\circledR}$ for finfishes should be between 0.2$0.35 \%$ based on their finding in Rainbow trout, while administration of $0.25 \%$ of nucleotides will increase growth, immune and stress responses of Caspian brown trout as reported by Kenari et al. (2013). On the contrary, Li et al. (2005) and Barros et al. (2015) suggested administration dose of nucleotide in fish diet at level $0.2 \%$ did not show significant effect on growth and immune function of juvenile Red drum and Nile tilapia.

There is a possibility of dietary nucleotides being capable of improving performance and immune functions of aquatic animal, some investigations could not confirm a positive performance and immune responses of nucleotide diet in other fish species as our finding in this study with Asian seabass. The inconsistent result might be caused by factor such as the application dose of nucleotide which could be effective to enhance the growth and immune parameters on some species of fish but did not effective for some other species. According to (Fuchs et al., 2015; Li and Gatlin, 2007), there are some factors which could be influence the effect of nucleotide diet for aquatic animal, such as dosage, method of administration, water quality, feeding rate, fish size or age class and genetic background of the animal.

In conclusion, the role of exogenous nucleotides in fish performance and immunity have not been establish and very diverse species to species. Therefore, further research is still required to determine the exact advantages of dietary nucleotides in Asian seabass using different dosages. 


\section{Acknowledgement}

We would like to thank Directorate General for Higher Education, Ministry of Research Technology and Higher Education, Republic of Indonesia, for funding the first author in her $\mathrm{PhD}$ at School of Animal and Veterinary Sciences, University of Adelaide Australia.

\section{References}

Andrino, K.G.S., A.E. Serrano Jr, and V.L. Corre Jr. 2012. Effects of Dietary Nucleotides on the Immune Response and Growth of Juvenile Pacific White Shrimp Litopenaeus vannamei (Boone, 1931). Asian Fisheries Science, 25: 180-192.

Barros, M.M., I.G. Guimaraes, L.E. Pezzato, R.O. Orsi, A.C.F. Junior, C.P. Teixeira, L.F. Fleuri, and C.R. Padovani. 2015. The effects of dietary nucleotide mixture on growth, performance, haematological and immunological parameters of Nile tilapia. Aquaculture Research, 46: 987-993.

Bondad-Reantaso, M.G., R.P. Subasinghe, J.R. Arthur, K. Ogawa, S. Chinabut, R. Adlard, Z. Tan, and M. Shariff. 2005. Disease and health management in Asian aquaculture. Veterinary Parasitology, 132: 249-272.

Burrells, C., P.D. Williams, and P.F. Forno. 2001 ${ }^{\mathrm{a}}$. Dietary nucleotides: a novel supplement in fish feeds 1. Effects on resistance to disease in salmonids. Aquaculture, 199 (1): 159-169.

Burrells, C., P.D. Williams, P.J. Southgate, and S.L. Wadsworth. 2001 ${ }^{\mathrm{b}}$. Dietary nucleotides: a novel supplement in fish feeds 2. Effects on vaccination, salt water transfer, growth rates and physiology of Atlantic salmon (Salmo salar L.). Aquaculture, 199: 171-184.

Cabello, F.C. 2006. Heavy use of prophylactic antibiotics in aquaculture: a growing problem for human and animal health and for the environment. Environmental Microbiology, 8 (7): 1137-1144.

Carver, J.D. and W.A. Walker. 1995. The role of nucleotides in human nutrition. Nutritional Biochemistry, 6: 58-72.

Cheng, Z., A. Buentello, and D.M.I. Gatlin. 2011. Dietary nucleotide influence immune responses and intestinal morphology of red drum Sciaenops ocellatus. Fish \& Shellfish Immunology, 30: 143-147.

Ellis, A.E. 1990. Lysozyme activity. In T.C. Stolen, P.D. Fletcher, B.S. Anderson, B.S. Roberson, \& W.B. Muiswinkel (Eds.), Technique in Fish Immunology (pp. 101-103). New Jersey, USA: SOS Publications.
Fuchs, V.I., J. Schmidt, M.J. Slater, J. Zentek, B.H. Buck, and D. Steinhagen. 2015. The effect of supplementation with polysaccharides, nucleotides, acidifiers and Bacillus strains in fish meal and soy bean based diets on growth performance in juvenile turbot (Scophthalmus maximus). Aquaculture, 437: 243-251.

Gatlin III, D.M. and P. Li. 2007. Nucleotides. Trowbridge, United Kingdom: Cromwell Press, Trowbridge UK.

Kenari, A.A., N. Mahmoudi, M. Soltani, and S.A. Kenari. 2013. Dietary nucleotide supplements influence the growth, haematoimmunological parameters and stress responses in endangered Caspian brown trout (Salmo trutta caspius Kessler, 1887). Aquaculture Nutrition, 19: 54-63.

Li, P., Burr, G.S., J. Goff, K.W. Whiteman, K.B. Davis, R.R. Vega, W.H. Neil, and D.M. Gatlin III. 2005. A preliminary study on the effects of dietary supplementation of brewers yeast and nucleotides, singularly or in combination, on juvenile red drum (Sciaenops ocellatus). Aquaculture Research, 36: 1120-1127.

Li, P. and D.M. Gatlin III. 2007. Dietary Supplementation of a Purified Nucleotide Mixture Transiently Enhanced Growth and Feed Utilization of Juvenile Red Drum, Sciaenops ocellatus. Journal of The World Aquaculture Society, 38 (2): 281-286.

Lin, Y-H., H. Wang, and S-Y. Shiau. 2009. Dietary nucleotide supplementation enhances growth and immune responses of grouper, Epinephelus malabaricus. Aquaculture Nutrition, 15: 117-122.

Low, C., S. Wadsworth, C. Burrells, and C.J. Secombes. 2003. Expression of immune genes in turbot (Scophthalmus maximus) fed a nucleotide-supplemented diet. Aquaculture, $221,23-40$.

Oliva-Teles, A. and P. Goncalves. 2001. Partial replacement of fishmeal by brewers yeast (Saccaromyces cerevisae) in diets for seabass (Dicentrarchus labrax) juveniles. Aquaculture, 202, 269-278.

Peng, M., W. Xu, Q. Ai, K. Mai, Z. Liufu, and K. Zhang. 2013. Effects of nucleotide supplementation on growth, immune responses and intestinal morphology in juvenile turbot fed diets with graded levels of soybean meal (Scophthalmus maximus L.). Aquaculture, 392-395: 51-58.

Russo, R. and R.P.E. Yanong. 2006. Dietary BetaGlucans and Nucleotides Enhance Resistance of Red-Tail Black Shark (Epalzeorhynchos bicolor, fam. Cyprinidae) to Streptococcus iniae Infection. World Aquaculture Society, 37 (3): 298-306. 
Sakai, M. 1999. Current research status of fish immunostimulants. Aquaculture, 172 (1): 6392

Sakai, M., K. Taniguchi, K. Mamoto, H. Ogawa, and M. Tabata. 2001. Immunostimulant effects of nucleotide isolated from yeast RNA on carp, Cyprinus carpio L. Journal of Fish Diseases, 24 (8): 433-438.

Secombes, C.J. 1990. Isolation of salmonid macophages and analysis of their killing activity. Techniques in fish immunology, 1: 137-154.

Shiau, S.-Y., J. Gabaudan, and Y.-H. Lin. 2015. Dietary nucleotide supplementation enhances immune responses and survival to Streptococcus iniae in hybrid tilapia fed diet containing low fish meal. Aquaculture Reports, 2: 77-81.

Siwicki, A., D. Anderson, and G. Rumsey. 1994. Dietary intake of immunostimulants by rainbow trout affects non-specific immunity and protection against furunculosis. Veterinary Immunology and Immunopathology, 41: 125-139.

Tahmasebi-Kohyani, A., S. Keyvanshokooh, A. Nematollahi, N. Mahmoudi, and H. PashaZanoosi. 2011. Dietary administration of nucleotides to enhance growth, humoral immune responses, and disease resistance of the rainbow trout (Oncorhynchus mykiss) fingerlings. Fish \& Shellfish Immunology, 30: 189-193.

Tahmasebi-Kohyani, A., S. Keyvanshokooh, A. Nematollahi, N. Mahmoudi, and H. PashaZanoosi. 2012. Effects of dietary nucleotides supplementation on rainbow trout (Oncorhynchus mykiss) performance and acute stress response. Fish Physiology and Biochemistry, 38: 431-440.

Welker, T.L., C. Lim, M. Yildirim-Aksoy, and P.H. Klesius. 2011. Effects of dietary supplementation of a purified nucleotide mixture on immune function and disease and stress resistance in channel catfish, Ictalurus punctatus. Aquaculture Research, 42: 18781889.

Yousefi, M., B. Abtahi, and A.A. Kenari. 2012. Hematological, serum biochemical parameters, and physiological responses to acute stress of Beluga sturgeon (Huso huso, Linnaeus 1785) juveniles fed dietary nucleotide. Comparative Clinical Pathology, 21: $1043-1048$ 